\title{
Careful neuropsychological testing reveals a novel genetic marker, GSTO1*C, linked to the pre-stage of Alzheimer's disease
}

\author{
Ellen Umlauf ${ }^{1}$, Eduard Rappold ${ }^{1}$, Bettina Schiller ${ }^{1}$, Petra Fuchs $^{2}$, Michael Rainer ${ }^{3}$, \\ Brigitte Wolf ${ }^{4}$ and Maria Zellner ${ }^{1}$ \\ ${ }^{1}$ Medical University of Vienna, Center of Physiology and Pharmacology, Institute of Physiology, Vienna, Austria \\ 2 SMZ Otto Wagner Spital, 3rd Department of Psychiatry, Vienna, Austria \\ ${ }^{3}$ SMZ Ost, Karl Landsteiner Institut für Gedächtnis- und Alzheimerforschung, Vienna, Austria \\ ${ }^{4}$ Medical University of Vienna, Surgery Research Laboratory, Department of Surgery, Vienna, Austria \\ Correspondence to: Maria Zellner, email: maria.zellner@meduniwien.ac.at \\ Keywords: Alzheimer's disease, MCl, CERAD-Plus, MMSE, well-defined control group, Gerotarget \\ Received: November 19, $2015 \quad$ Accepted: May 25, $2016 \quad$ Published: June 01, 2016
}

\section{ABSTRACT}

Approximately $\mathbf{3 0}$ million people currently suffer from late-onset Alzheimer's disease (LOAD) worldwide. Twin studies demonstrated that 60 to $80 \%$ of LOAD is genetically determined, $20 \%$ of which remaining unassigned. This case-control study included 118 cognitively healthy controls, 52 patients with mild cognitive impairment (MCI; the pre-stage of LOAD) and 71 LOAD patients. The participants were genotyped for the genetic LOAD marker apolipoprotein E4 (APOE4) and the single-nucleotide polymorphism rs4925 in glutathione S-transferase omega-1 (GSTO1). Additive logistic regression showed a novel, statistically significant association of the major allele GSTO1 *C with MCI (OR1.9; $p=0.032)$. However, identification of significant SNPdisease relations required well-defined study groups. When classifying participants solely by the short Mini Mental State examination (MMSE), the associations of GSTO1*C and the reference marker APOE4 with MCI were cancelled. Moreover, even identifying only the control group by MMSE nullified a statistically significant association (OR1.8; $p=0.045)$ between GSTO1 $* C$ and LOAD. In contrast, these statistical relations were retained when the detailed Consortium to Establish a Registry for Alzheimer's Disease (CERAD-PIus) test battery was used. Hence, besides proposing rs4925 as a genetic marker for cognitive impairment, this work also emphasized the importance of carefully characterized controls in addition to well-diagnosed patients in casecontrol studies.

\section{INTRODUCTION}

Late-onset Alzheimer's disease (LOAD), a multifactorial neurodegenerative disorder, is the most prominent form of dementia among the elderly $(>65$ years), and its incidence is expected to double within the next 25 years. Currently, every third octogenarian in the industrialized countries suffers from LOAD [1]. A much rarer disease variant referred to as early-onset $\mathrm{AD}$ (EOAD) develops at an earlier age (per definition $<65$ years) and shows a more rapid clinical decline [2]. Both disease variants are characterized neuropathologically by extracellular senile plaques containing $\beta$-amyloid
$(\mathrm{A} \beta)$ and intracellular neurofibrillary tangles comprising hyperphosphorylated tau protein [3]. Three proteins including amyloid precursor protein, presenilin 1 and presenilin 2 play an important role in the formation of $A \beta$ [4]. However, mutations in these three proteins have been found only in EOAD but not in LOAD [5], which latter variant nonetheless, shows heritability between 60 to $80 \%$ in twin studies [6]. Nevertheless, genome-wide [7-13] and candidate-driven studies [14] demonstrated that several single-nucleotide polymorphisms (SNP) associate with the disease. Nevertheless, $20 \%$ of the genetic risk remains undetected [15] and completing a shortlist of LOADassociated SNP candidates could further investigation on 
their potential roles in the etiology of LOAD.

Definite diagnosis of a disease status is crucial but this is only possible post mortem in LOAD. Thus, routinely, examination of probable LOAD is based on medical and familial history, exclusion of other causes, brain imaging techniques (CT, MRI, PET) and neuropsychological examination of cognitive functions $[16,17]$. The latter are assessed by a wide variety of tests, e.g. the Mini Mental State Examination (MMSE) and the extended Consortium to Establish a Registry for Alzheimer's Disease test battery (CERAD-Plus). MMSE is a ten-minute screening test and comprises 30 questions that are totaled up into a single raw score [18]. In contrast, the detailed CERAD-Plus, which includes the MMSE component, takes approximately one hour. It lists z-values of fourteen subtests that are corrected for age, gender, and education [19]. Despite the limitations inherent to MMSE, it is nevertheless still used as the sole criterion for classification of cognitively healthy controls in many studies $[8,20-22]$. The same neuropsychological tests are used for identification of the preceding stage of LOAD referred to as mild cognitive impairment (MCI), which is defined as "not normal, not demented" [23]. It represents the transitional phase between cognitive health and LOAD and, thus, is a heterogeneous group that includes converters to LOAD, reverters to normal cognition and stable MCI patients. Patients that are likely to progress to probable LOAD are mainly characterized by memory impairment [24].

The most important genetic marker for LOAD is the SNP pair allelic variant APOE4 (rs429358, rs7412), translating into $\operatorname{Arg} 112$ and $\operatorname{Arg} 158$. Two other major alleles of $A P O E$ have been identified; with E3 (Cys112, Arg158) being the most common and the E2 variant (Cys112, Cys158) representing a rather rare but protective allele [25]. One copy of the APOE4 allele confers a fourfold increased risk for LOAD, while two copies raise the risk tenfold [26]. Likewise, this allele is associated with a 1.4-fold increased risk for MCI [27].

A further SNP, which we recently found to associate with the APOE4-negative phenotype of LOAD [28], is $\operatorname{rs} 4925\left(G S T O{ }^{*} C>A\right)$ and lies in the glutathione S-transferase omega-1 (GSTO1) gene. However, while we found a significant association of the major allele variant $G S T O{ }^{*} C$, originally the minor variant $G S T O 1{ }^{*} A$ was shown to delay age-at-onset of LOAD [20, 29]. Nonetheless, association of the SNP with neither onset nor risk was confirmed by other studies [7, 8, 10-12, 30-33].

In the present study, we investigated whether the allele $G S T O 1{ }^{*} C$ could also serve as genetic risk marker for MCI, in addition to LOAD. The study participants were classified using established criteria, and two SNPs were genotyped by DNA amplifying techniques. Additive logistic regression results are discussed with reference to other association studies and commonly used classification strategies. A potentially negative impact on identifying significant, established and novel SNPdisease associations is illustrated by a comparison of the neuropsychological tests CERAD-Plus and MMSE.

\section{RESULTS}

\section{The allele $G S T O 1{ }^{*} \mathrm{C}(\mathrm{rs4925})$ is significantly associated with MCI}

Previously, we showed that $G S T O 1{ }^{*} C$ significantly associated with the APOE4-negative LOAD phenotype [28]. Since MCI represents a transitional phase between cognitive health and LOAD, similarities in genetic characteristics to the latter might be expected. Hence, we investigated the prevalence of this allele in MCI.

We enrolled $52 \mathrm{MCI}$ patients and 113 age- and sexmatched controls between the age of 65 and 95 years, who completed the CERAD-Plus test battery including MMSE and underwent clinical examination. MCI cases were diagnosed by a physician and a psychiatrist or psychologist according to the criteria of the consensus conference in Stockholm in 2003 [23] and the CERAD Diagnostic Manual for Dementia [34]. Neuropsychological criteria of MCI were an MMSE $\geq 24$, not demented, intact activities of daily living, and impairment in at least two domains of memory with $\mathrm{z} \leq-1.29 \mathrm{SD}$ (CERAD) similar to the diagnostic comprehensive criteria [35]. The control test persons were classified as normal when MMSE $\geq 26$ and, at most, one neuropsychological measure of the CERADPlus test battery fell more than 1.28 SD below ageappropriate norms $(\mathrm{z} \leq-1.29 \mathrm{SD})$ in any cognitive domain [35]. Their MMSE values were in the range between 26 and 30, similar to the normative group for the German CERAD-Plus test battery $[19,36]$, see demographic overview, Table 1. Additionally, the study participants were genotyped for APOE4 and rs4925 (GSTO1) using DNA amplification procedures. Both SNPs were consistent with Hardy-Weinberg equilibrium in both test groups.

Logistic regression applied to the reference genetic marker $A P O E 4$ yielded an OR 3.0 and a statistical significance $p=0.005$. A logistic regression for $G S T O 1{ }^{*} C$ showed an OR 1.9 and $p=0.032$ (Table 2).

Hence, $G S T O{ }^{*} \mathrm{C}$ appeared to moderately associate with MCI. APOE4 is also a published genetic marker for MCI [27] and, thus, confirmed the diagnosis procedure for the present study participant set. However, association of $G S T O 1^{*} C$ with cognitive impairment was previously not observed [7, 8, 10-12, 30-33]. In order to identify potential reasons for these discrepancies, we compared the classification efficiencies of commonly used study designs and their impact on the significance of the associations between $A P O E 4$ or $G S T O{ }^{*} C$ and MCI. 
Table 1: Demographic overview and rs4925 genotype characteristics of control and MCI sample donors.

\begin{tabular}{|c|c|c|c|c|c|c|c|c|c|}
\hline \multirow{2}{*}{ Samples } & \multirow[t]{2}{*}{$\mathbf{N}$} & \multirow{2}{*}{$\begin{array}{l}\text { Mean age } \\
\text { (SD, age range) }\end{array}$} & \multirow{2}{*}{$\begin{array}{l}\text { Gender Nf } \\
(\%)\end{array}$} & \multirow{2}{*}{$\begin{array}{l}\text { Mean } \\
\text { MMSE } \\
(\text { SD) }\end{array}$} & \multirow{2}{*}{$\mathrm{AF}(A P O E 4)$} & \multirow{2}{*}{$\begin{array}{l}\text { N } E 4 / E 4 \\
(\%)\end{array}$} & \multicolumn{3}{|c|}{$\begin{array}{l}\text { rs4925 } \\
\text { genotype, } \mathrm{N}\end{array}$} \\
\hline & & & & & & & $\mathrm{CC}$ & $\mathrm{CA}$ & AA \\
\hline Controls & 113 & $\begin{array}{l}79.1 \\
(8.0,65-95) \\
\end{array}$ & $77(68.1)$ & $28.7(1.2)$ & 0.066 & $0(0.0)$ & 53 & 52 & 8 \\
\hline MCI & 52 & $\begin{array}{l}80.8 \\
(6.5,67-91)\end{array}$ & $41(78.8)$ & $27.4(1.3)$ & 0.173 & $2(3.9)$ & 33 & 18 & 1 \\
\hline
\end{tabular}

Fifteen controls were heterozygous for APOE4 (13.3\%) and 14 MCI patients were heterozygous for APOE4 (26.9\%). Abbreviations: N...number, SD ... standard deviation, f... female, AF...allele frequency, E4/E4 ...APOE4/APOE4 homozygous genotype

Table 2: Association (logistic regression analyses) of $G S T O 1 * C$ or $A P O E 4$ with MCI.

\begin{tabular}{|l|l|l|l|}
\hline SNP & B(SE) & Odds ratio (95\% CI) & Sign. \\
\hline rs429358 $($ APOE4 $)$ & $1.084(0.383)$ & $3.0(1.4-6.3)$ & 0.005 \\
\hline rs4925 (GSTO1*C) & $0.651(0.304)$ & $1.9(1.1-3.5)$ & 0.032 \\
\hline
\end{tabular}

Binary logistic regression analyses comparing 113 controls and $52 \mathrm{MCI}$ patients were performed on the GSTO1*C allele or the $A P O E 4$ allele.

Abbreviations: B...Beta value, SE...standard error, CI... confidence interval, Sign. ... significance

\section{The CERAD composite score outperforms MMSE in control/MCI classification}

As indicated earlier, many LOAD biomarker studies have defined their control groups, partly or entirely, on the sole basis of MMSE, e.g. [8, 20-22]. However, it was reported that MMSE was a screening test for intermediate to severe LOAD [37] and had substantial false-negative rates [38]. Therefore, we examined, whether individual neuropsychological tests, especially MMSE, achieved the classification accuracy required for detecting significant associations of APOE4 or $G S T O{ }^{*} \mathrm{C}$ with cognitive impairment. First, classifications based on either MMSE or CERAD-Plus (without MMSE) were analyzed for their agreement with the group assignment determined by the standard consensus [23], CERAD [34] and comprehensive criteria [35], as described above. Afterward, the respective control and MCI classifications defined by either of the two neuropsychological tests were used to test whether the associations between $A P O E 4$ or $G S T O{ }^{*} C$ and $\mathrm{MCI}$ observed in the previous section were retained.

The test persons described in the first section had been classified according to standardized consensus criteria $[23,34,35]$, using information from clinical examination, medical history and neuropsychological testing. However, in order to ensure a tighter focus on the transition between cognitive health and MCI, the threshold MMSE $\geq 24$ for MCI patients of the standardized criteria $[23,34,35]$ was raised to MMSE $\geq 26$. Consequently, 49 MCI patients and 113 age- and sex-matched controls were used for evaluation (Supplementary Table 1).

Logistic regression analyses were applied to analyze the degree of consistency between the classifications by MMSE or CERAD-Plus (without MMSE) and the standardized comprehensive criteria [23, 34, 35]. The logistic regression of the MMSE showed an accuracy of $74.1 \%$ and a significance $p=4.6 \mathrm{E}-08$ (Methods). The area under the curve (AUC) of the receiver operating curve (ROC) was 0.757 , using a cut-off at 0.5 in the logistic regression analysis. The latter is equivalent to a cut-off MMSE $\leq 27$ for classification of MCI. In contrast, a logistic regression of five CERAD subtests (backward likelihood ratio of 13 CERAD subtests excluding MMSE) calculated a prediction model for MCI with an accuracy of $89.5 \%, p=2.1 \mathrm{E}-25$ and an AUC $=0.965$ (cut-off 0.5 ). The calculated predicted probability for MCI for each individual can take values between 0 and 1 ( $>0.5$ for $\mathrm{MCI}$ ) and was termed "CERAD composite score". Table 3 shows that the five CERAD subtests Z Wordlist total, $\mathrm{Z}$ WL savings, $\mathrm{Z} W \mathrm{~W}$ recognition, and $\mathrm{Z}$ Figure recall are part of this composite score. The statistical approach applied here was similar to the one used for computing a previous CERAD score for the identification of early LOAD [39].

Therefore, MMSE was only $83 \%$ as accurate as the CERAD composite score and it was important to determine whether the two test's increased error rates would nullify the association of $A P O E 4$ and $G S T O 1{ }^{*} C$ with MCI. 
Table 3: Association of CERAD (binary logistic regression analysis) with the classification of 113 controls and $49 \mathrm{MCI}$ patients (CERAD composite score).

\begin{tabular}{|l|l|l|l|}
\hline CERAD Subtest & B(SE) & Odds ratio (95\% CI) & Sign. \\
\hline Z verbal Fluency Animals & $-0.644(0.311)$ & $0.5(0.3-0.97)$ & 0.038 \\
\hline Z Wordlist total & $-2.222(0.536)$ & $0.1(0.04-0.3)$ & $3.4 \mathrm{E}-5$ \\
\hline Z WL savings & $-1.132(0.359)$ & $0.3(0.2-0.7)$ & 0.002 \\
\hline Z WL recognition & $-0.790(0.320)$ & $0.5(0.2-0.9)$ & 0.014 \\
\hline Z Figure recall & $-1.125(0.271)$ & $0.3(0.2-0.6)$ & $3.2 \mathrm{E}-5$ \\
\hline
\end{tabular}

Stepwise logistic regression analysis (backward elimination, exclusion criterion: $p \geq 0.05$; inclusion criterion: $\mathrm{p}<0.05$; cutoff value $=0.5)$ comparing 113 controls $($ MMSE $\geq 26)$ and 49 MCI patients (MMSE $\geq 26)$ was done on all $13 \mathrm{z}$-transformed CERAD subtests (excluding MMSE). Five subtests remained in the equation and performed much better (accuracy 89.5\%) than the MMSE test (accuracy 74.1\%); $\mathrm{R}^{2}=0.632$ (Hosmer\&Lemeshow), $\mathrm{R}^{2}=0.539$ (Cox\&Snell), $\mathrm{R}^{2}=0.763($ Nagelkerke), Model chi-squared $=125.53$ and $p=2.1 \mathrm{E}-25)$. The resulting CERAD composite score (0 to 1$)$ is represented by the probability $\mathrm{P}$ for diagnosis of MCI: $\mathrm{P}(\mathrm{MCI})=1 /\left(1+\mathrm{e}^{\wedge}(-(-1.718-0.644 * \mathrm{Z}\right.$ verbal Fluency Animals $-2.222 * \mathrm{Z}$ Wordlist total $-1.132 * \mathrm{Z}$ WL savings $-0.790 * \mathrm{Z}$ WL recognition $-1.125 * \mathrm{Z}$ Figure recall) $)), \mathrm{P}(\mathrm{MCI})>0.5$ implies $\mathrm{MCI}$ classification.

Abbreviations: B...Beta value, SE...standard error, CI... confidence interval, Sign. ... significance

Table 4: Association of $G S T O 1 * C$ or $A P O E 4$ with the MCI classification based either on MMSE or the CERAD composite score (49 MCI patients, 113 controls).

\begin{tabular}{|l|l|l|l|l|}
\hline Test & SNP & B(SE) & Odds ratio (95\% CI) & Sign. \\
\hline MMSE & APOE4 $(\mathrm{rs} 429358)$ & $0.437(0.384)$ & $1.6(0.7-3.3)$ & 0.255 \\
\hline & GSTO1 $* C(\mathrm{rs} 4925)$ & $0.397(0.307)$ & $1.5(0.8-2.7)$ & 0.196 \\
\hline CERAD & APOE4 $(\mathrm{rs} 429358)$ & $1.128(0.386)$ & $3.1(1.5-6.6)$ & 0.004 \\
\hline & GSTOI $*$ (rs4925) & $0.636(0.317)$ & $1.9(1.02-3.5)$ & 0.045 \\
\hline
\end{tabular}

Binary logistic regression analyses comparing controls and MCI patients that had been assigned either on the basis of the MMSE score (Methods) or the CERAD composite score (Table 3) were performed on the APOE4 allele or the GSTO1*C allele (rs4925). The genetic markers APOE4 and GSTO1 ${ }^{*} C$ are only significantly associated with the CERAD composite score-based classification (lower panel).

Abbreviations: B...Beta value, SE...standard error, CI... confidence interval, Sign. ... significance

\section{MMSE fails to detect the associations of $A P O E 4$ and GSTO1*C with MCI}

Next, we investigated whether classification by either MMSE or the CERAD composite score would detect the association of APOE4 and GSTO1 ${ }^{*} C$ with $\mathrm{MCI}$. For this purpose, we used the group assignments obtained from the individual neuropsychological tests in the previous section. The respective group allocations were related to either $A P O E 4$ or $G S T O 1{ }^{*} \mathrm{C}$ as predictors, using logistic regression analyses.

The results showed an OR 1.6 and $p=0.255$ for the association of the LOAD-specific APOE4 variant with MMSE (Table 4, upper panel). On the other hand, the logistic regression of $A P O E 4$ with the CERAD composite score revealed an OR 3.1 and $p=0.004$ (Table 4, lower panel). Similar regression analyses of $G S T O 1{ }^{*} C$ exposed an OR 1.5 and $p=0.196$ for MMSE (Table 4, upper panel), while the CERAD composite score showed an OR 1.9 and $p=0.045$ (Table 4, lower panel).

These results demonstrated that classification by MMSE nullified the association of $A P O E 4$ and $G S T O 1{ }^{*} C$ with MCI. Next, we looked into whether an association of $G S T O 1{ }^{*} C$ with LOAD would also be canceled when the use of MMSE for group assignment was restricted to the controls in a LOAD-control study.

\section{Classifying controls by MMSE annulled the association of $G S T O 1{ }^{*} C$ with $\mathrm{LOAD}$}

MMSE alone is often used to classify healthy controls, applying a threshold of MMSE $\geq 26$, e.g. [8, 20-22], which also covers the MMSE range for MCI patients. Therefore, we included a mathematical approach to analyze the association of $G S T O 1{ }^{*} C$ and $A P O E 4$ with $\mathrm{LOAD}$, in dependence of the classification procedure for the control group. For this purpose, a partially new study set comprising 69 cognitively healthy individuals (64 of which were identical with those in the previous sections) and 71 newly recruited LOAD patients within the age range of 65 to 95 years was genotyped for $G S T O 1{ }^{*} C$ and APOE4 (Supplementary Tables 2 and 3). LOAD patients were diagnosed according to the Neurological and Communicative Disorders and Stroke and the Alzheimer's Disease and Related Disorders Association criteria (NINCDS-ADRDA) and controls were classified using the above standardized comprehensive criteria, [50] and $[19,33,34]$. Logistic regression would show whether $G S T O{ }^{*} C$ and $A P O E 4$ were associated with the LOAD phenotype. Thereafter, our previous group of $49 \mathrm{MCI}$ 
Table 5: Primers used for the $A P O E$ PCR and the ARMS PCR for rs4925.

\begin{tabular}{|l|l|l|l|}
\hline primer & Sequence & $\begin{array}{l}\text { Tm } \\
\left({ }^{\circ} \mathbf{C}\right)\end{array}$ & $\begin{array}{l}\text { Conc. } \\
(\boldsymbol{\mu} \mathbf{M})\end{array}$ \\
\hline \multirow{2}{*}{ APOE-FW } & $\begin{array}{l}\text { GACGCGGGACGGCTGTCCAAGGAGCTGCAGG } \\
\text { CGACGCAGGCCCGGCTGGACGCGGACATGGA } \\
\text { GGA }\end{array}$ & 99.6 & 1.0 \\
\hline APOE-RV & AGGCCACGCTCGACGCCCTCGCGGGCCCCGGCCTGGTACACT & 90.7 & 1.0 \\
\hline GSTO1-FWinnerA & TATTAGAAGCCAAAATAAAGAAGACTACGA & 56 & 0.90 \\
\hline GSTO1-RVouter & GAAAGTGGGAATATAAAGAAAAGAATAGGA & 56 & 0.60 \\
\hline GSTO1-FWouter & CGATACAGTTAGCCATAAACTGATAAACTAA & 56 & 0.60 \\
\hline GSTO1-RVinnerC & ATTCTTTACGAAATTCTTCTTTTAGGCTAG & 56 & 0.84 \\
\hline
\end{tabular}

The resulting fragments for the $A P O E$ genotyping are explained in Methods. The ARMS PCR for rs4925 generates a total fragment of the two outer primers $(239 \mathrm{bp})$ that serves as a positive control, a major C allele-specific fragment (132bp) and/ or a minor A allele-specific fragment (167bp). All sequences are given in the 5' to 3' direction.

Abbreviations: Tm... melting temperature, Conc. ... concentration, $\mu \mathrm{M} \ldots$.. 10E-6 mol/L

patients that was classified according to the standardized comprehensive criteria $[19,33,34]$ and had an MMSE $\geq$ 26 was added to the group of healthy controls in this study, now totaling 118 individuals. The rationale behind this strategy was to determine by logistic regression whether the strength and significance of the original association between $G S T O{ }^{*} C$ or the published reference allele APOE4 and LOAD would be nullified or reduced.

The results of a logistic regression of the original 69 controls and 71 LOAD patients revealed a significant association of $G S T O{ }^{*} C$ with the disease, OR 1.8 and $p$ $=0.045$. The values for association between the reference allele APOE4 and LOAD were OR 6.7 and $p=5.0$ E-7 (Supplementary Table 3, Panels A1 and A2). Thereafter, $49 \mathrm{MCI}$ patients with MMSE $\geq 26$ were added to the 69 controls and logistic regression with the enlarged control group and 71 LOAD patients was performed. This resulted in the elimination of the originally significant association of $G S T O 1^{*} C$, OR $1.4, p=0.170$. The APOE4 association values were reduced to OR 3.4 and the significance deteriorated to $p=3.4$ E-5 (Supplementary Table 3, Panels $\mathrm{B} 1$ and B2).

Hence, classification of the control group on the basis of an MMSE threshold seemed to cancel a significant association of $G S T O{ }^{*} C$ and LOAD, and additionally served to decrease the OR for the reference marker APOE4 in LOAD. These findings are discussed below.

\section{DISCUSSION}

In the present study, we showed for the first time a significant association of $G S T O 1{ }^{*} C$ with mild cognitive impairment. This novel observation, however, could only be made following careful neuropsychological examinations undertaken using the standardized comprehensive criteria [23, 34, 35]. In addition, the strongest genetic marker for late onset Alzheimer's disease, APOE4 [40], also associated with MCI, confirming that this group represented a preceding stage of LOAD. Moreover, GSTO1*C significantly associated with LOAD, but this relationship could only be exposed using established patient norms (NINCS-ADRDA) and strict control criteria not offered by the MMSE protocol. We compared the CERAD and MMSE neuropsychological tests and found the former to be superior in classifying participants for studying cognitive impairment. Indeed, patient and control classifications based on MMSE alone failed to expose the association between $G S T O{ }^{*} C$ and APOE4 with MCI. Thus, we underscored on a genetic basis the inutility of applying MMSE alone to the characterization of healthy controls in studies of cognitive impairment patients.

In reference to our comparison between the neuropsychological tests, CERAD and MMSE, our study cautioned against the rather common use of MMSE as the sole classification criterion, especially for the identification of controls (MMSE $\geq 26$ ). MMSE's limited accuracy $(74.1 \%)$ with regard to distinguishing the cognitively healthy from MCI resulted in the failure to detect significant SNP/MCI and SNP/LOAD associations. The latter's shortcoming was caused by MCI cases falsely classified as controls. The MCI's resemblance to LOAD and their percentage in the whole control group determined the negative effect on the SNP/LOAD association. In contrast, CERAD performed much better in control/MCI classification, with an accuracy of $89.5 \%$. As expected, especially the episodic memory-related CERAD subtests were significantly associated with MCI (Z Wordlist (WL) total, Z WL savings, Z WL recognition, Z Figure recall), suggesting that they were affected first during disease development [41].

However, our findings that $G S T O{ }^{*} \mathrm{C}$ associated with an increased risk for MCI and LOAD are in contrast to other investigations, which only observed an association with age-at-onset of $\operatorname{LOAD}[29,30]$ or did not find any relevance for LOAD [7, 8, 10-12, 31-33]. We speculate that these differing results were caused by several factors (discussed below), which altered group assignments across 
the studies.

It has been demonstrated previously that LOAD overlaps with several cerebrovascular pathologies such as regional cerebral hypoperfusion and cerebrovascular lesions [42]. Indeed, in a case/control study, the minor GSTOI*A/A genotype of rs4925 showed elevated frequency in vascular dementia $(\mathrm{VaD})$ patients [43]. Thus, an increased $\mathrm{VaD}$ proportion in LOAD cases would attenuate the $G S T O 1{ }^{*} C$ prevalence and might conceal its association with LOAD.

To date, the majority of MCI or LOAD patients in case/control studies is classified on the basis of neuropsychological and/or brain imaging tests. In particular, there is a multitude of neuropsychological tests that quantify different cognitive functions, which certainly affects case- as well as control definitions. For instance, correlation between CDR and CERAD showed only medium effect sizes around $r=-0.5[44,45]$. As a consequence, associations of SNPs with MCI or LOAD may vary between case/control studies.

On the other hand, samples for the control group are sometimes drawn from younger, population-based cohorts and age-matching with cases is bypassed $[8,10$, 29]. We estimated that, as a consequence, up to about $10 \%$ of the control group may show a LOAD-related genetic profile. This value was based on the assumption that approximately $35 \%$ of a 40 to 50 -year old population in industrialized countries will reach the age of 85 [46] at which time roughly $30 \%$ would probably suffer from LOAD. This translates to a $10 \%$ risk for LOAD in all living 40 to 50 -year olds. This confounding effect may be enhanced by an increased morbidity and mortality conferred by other SNP-associated diseases. For instance, $A P O E 4$ elevates the risk for cardiovascular disease [47] and, thus, increases mortality. Therefore, the $\mathrm{AF}(A P O E 4)$ in an age-matched reference group is expected to be reduced as compared to younger population-based cohorts. Accordingly, the AF(APOE4) of the control group in the present study (0.065) was only half the AF (0.11) of the average Austrian population [48].

From the collected evidence presented here, $G S T O 1{ }^{*} C$ (rs4925) could turn out to be a genetic risk factor for impairment of cognition in the elderly. Moreover, our finding that MMSE alone was not accurate enough to assign participants to the cognitively healthy control group may foster refinement of case/control study designs.

\section{MATERIALS AND METHODS}

\section{Ethics statement}

Investigation has been conducted in accordance with the ethical standards and according to the Declaration of
Helsinki and according to national and international guidelines and has been approved by the authors' institutional review board.

\section{Study participants}

Study participants between 65 and 95 years were recruited from Greater Vienna (Austria) and were all of Caucasian origin. LOAD patients were enrolled in geriatric care, retirement and nursing homes. Control individuals and $\mathrm{MCI}$ patients were recruited from spouses of LOAD patients, in retirement homes and by word of mouth.

All study participants underwent clinical examination including a review of the medical history to confirm the absence of systemic disorders. Neuropsychological testing was performed using the German CERAD test battery [49], which included MMSE, on the day of blood sampling.

71 clinically suspected LOAD patients additionally underwent structural brain scanning using MRI to exclude other causes of cognitive impairment like stroke or tumors. Diagnoses of probable LOAD were established by a physician and a psychiatrist or psychologist according to the criteria by the US National Institute of Neurological and Communicative Disorders and Stroke and the Alzheimer's Disease and Related Disorders Association (NINCDS-ADRDA) [50], which are equivalent to the standardized CERAD criteria [51]. LOAD patients showed two or more severe deficits in cognition, [34], and age between 65 and 95 years. Further selection criteria were severe temporal lobe atrophy on MRI and exclusion of other forms of dementia (i.e. VaD).

52 MCI patients were diagnosed by a physician and a psychiatrist or psychologist according to the criteria of the consensus conference in Stockholm in 2003 [23] and the Diagnostic Manual for Dementia [34]. Neuropsychological criteria of MCI were an MMSE $\geq$ 24 , not demented, intact activities of daily living, and impairment in at least two domains of memory with $\mathrm{z} \leq$ -1.29 (CERAD) using diagnostic comprehensive criteria [35].

118 control subjects were classified as normal by a physician and a psychiatrist or psychologist when MMSE $\geq 26$ and, at most, one neuropsychological measure of the CERAD test battery fell greater than 1.28 SD below age-appropriate norms in any cognitive domain (Table 1, Supplementary Table 2). Their MMSE values were in the range between 26 and 30, similar to the normative group for the German CERAD-Plus test battery [19, 36].

The study was approved by the ethics commission of the city of Vienna, Austria, EK-04-070-0604 and EK09/219/1209. Each participant and/or legal guardian was advised of the purpose and procedures of the study and written informed consent was obtained prior to initiating the study in accordance with the principles of 
the Declaration of Helsinki.

\section{Genotyping}

Genomic DNA from whole blood was isolated according to the manufacturer's protocols using either QIAamp DNA Mini Kit (Qiagen) or PerfectPure DNA Blood Kit (5Prime). APOE4 (rs429358, rs7412) genotyping was done according to [52] modified by $\mathrm{R}$. Crook. In brief, genomic DNA was amplified using the APOE-FW primer and the APOE-RV primer (Table 5), the kit sample buffer, 10\% DMSO, $200 \mu \mathrm{M}$ dNTPs, 15 - 40 ng genomic DNA and 0.25 units HotStarTaq Plus DNA polymerase (Qiagen). PCR conditions on a Mastercycler epgradient $\mathrm{S}$ (Eppendorf) were: $94^{\circ} \mathrm{C}$ for $5 \mathrm{~min}, 45$ cycles: $94^{\circ} \mathrm{C}$ for $20 \mathrm{~s}, 66.5^{\circ} \mathrm{C}$ for $30 \mathrm{~s}, 72^{\circ} \mathrm{C}$ for $35 \mathrm{~s}$, final extension: $72^{\circ} \mathrm{C}$ for $10 \mathrm{~min}$. After HhaI digestion (Fermentas), 3\% TBE agarose gel electrophoresis $(0.025 \mu \mathrm{l} / \mathrm{ml}$ Midori Green, NIPPON Genetics or $0.05 \mu \mathrm{l} / \mathrm{ml}$ peqGREEN, peqlab) and documentation (Bio-Visionsystem, peqlab), the fragment patterns were interpreted as follows: $A P O E 2 /$ APOE2 144bp, 96bp; APOE3/APOE3 144bp, 48bp; APOE4/APOE4 72bp, 48bp; APOE2/APOE3 144bp, 96bp, 48bp; APOE3/APOE4 144bp, 72bp, 48bp; APOE2/APOE4 144bp, 96bp, 72bp, 48bp. The SNP rs4925 was genotyped using Amplification-refractory mutation system PCR [53], which allowed the detection of both SNP variants in a single reaction tube. The PCR reaction volume was $10 \mu \mathrm{l}$, using the kit sample buffer, 15-40 ng genomic DNA, $200 \mu \mathrm{M}$ dNTPs, four primers (Table 5) and 0.25 units HotStarTaq Plus DNA polymerase (Qiagen). After an initial denaturation step at $95^{\circ} \mathrm{C}$ for $10 \mathrm{~min}$, a touch down PCR was run $\left(10\right.$ cycles: $95^{\circ} \mathrm{C}$ for $45 \mathrm{~s}, 68^{\circ} \mathrm{C}$ for $45 \mathrm{~s}, 72^{\circ} \mathrm{C}$ for $1 \mathrm{~min} 30 \mathrm{~s}$; 10 cycles: $95^{\circ} \mathrm{C}$ for $45 \mathrm{~s}, 58^{\circ} \mathrm{C}$ for $45 \mathrm{~s}, 72^{\circ} \mathrm{C}$ for $1 \mathrm{~min} 30 \mathrm{~s}$; 18 cycles: $95^{\circ} \mathrm{C}$ for $45 \mathrm{~s}, 54^{\circ} \mathrm{C}$ for $45 \mathrm{~s}, 72^{\circ} \mathrm{C}$ for $1 \mathrm{~min} 30 \mathrm{~s}$; 9 cycles: $95^{\circ} \mathrm{C}$ for $35 \mathrm{~s}, 52^{\circ} \mathrm{C}$ for $45 \mathrm{~s}, 72^{\circ} \mathrm{C}$ for $1 \mathrm{~min}$; final extension: $72^{\circ} \mathrm{C}$ for $\left.10 \mathrm{~min}\right)$. The PCR reaction was loaded on a $2.5 \%$ TBE agarose gel and analyzed as described above. The resulting PCR fragments corresponded to the positive control generated by the two outer primers (239bp), the major $\mathrm{C}$ allele (132bp) and the minor A allele (167bp).

\section{Statistics}

The calculations of associations between $G S T O 1{ }^{*} \mathrm{C}$ (rs4925) or APOE4 (rs429358) and MCI are part of an exploratory study, for which calculation of the statistical power was omitted. Further testing in a new sample cohort will be necessary to confirm our findings. In order to estimate the statistical power for the association of $A P O E 4$ or $G S T O 1 * C$ with $\mathrm{LOAD}$, we used simulation of a binary logistic regression model based on our previously published data [28]. The power of the association of APOE4 with LOAD was predicted to be $87 \%$ for 16 individuals per group and reached $100 \%$ for the participant numbers used in this study. The association of GSTO1 *C with LOAD was also considered exploratory and therefore, its statistical power of 55\% was accepted. [R] packages plyr [54] and HardyWeinberg [55] were used for calculations [56].

Pearson's chi-squared test was used to test for deviation from the Hardy-Weinberg equilibrium. Binary logistic regressions were used to analyze the association of the SNP of interest with the respective disease state.

Binary logistic regressions comparing 113 controls (MMSE $\geq 26$ ) and $52 \mathrm{MCI}$ patients (MMSE $\geq 24$ ) were done on the $G S T O 1{ }^{*} C$ allele (rs4925) or the $A P O E 4$ allele. Of these controls, 64 individuals were identical with those in the Control/LOAD analysis below. Next, both neuropsychological tests, MMSE and CERAD (without MMSE) were tested for their ability to correctly classify study individuals. In order to focus on the transition between cognitive health and MCI, MCI patients with MMSE $\geq 26$ were selected, giving a total of $49 \mathrm{MCI}$ patients. Firstly, a logistic regression comparing 113 controls (MMSE $\geq 26$ ) and 49 MCI patients (MMSE $\geq$ 26) was performed on MMSE values. The results for the prediction model were: $\mathrm{B}(\mathrm{SE})=-0.781(0.152)$; OR 0.5 (0.3-0.6); $p=7.94$ E-07; accuracy $=74.1 \%$; correlation coefficients: $\mathrm{R}^{2}=0.175$ (Hosmer\&Lemeshow), $\mathrm{R}^{2}=$ 0.168 (Cox\&Snell), $\mathrm{R}^{2}=0.238$ (Nagelkerke); model chisquared $=29.89$ and $p=4.6$ E-08. MMSE-based MCI classification was calculated using a predicted probability cut-off value $>0.5$, which corresponded to MMSE $\geq 28$ as cut-off for the logistic regression. Secondly, a stepwise logistic regression analysis with backward elimination (exclusion criterion: $p \geq 0.05$; inclusion criterion: $p$ $<0.05$; cut-off value $=0.5$ ) comparing 113 controls (MMSE $\geq 26)$ and 49 MCI patients (MMSE $\geq 26$ ) was done on all 13 z-transformed CERAD subtests (excluding MMSE). Five subtests remained in the equation and the value for the predicted probability for MCI was called "CERAD composite score" (for details see Table 3 and legend): accuracy $=89.5 \%$; correlation coefficients: $\mathrm{R}^{2}=$ 0.632 (Hosmer\&Lemeshow), $\mathrm{R}^{2}=0.539$ (Cox\&Snell), $\mathrm{R}^{2}=0.763$ (Nagelkerke), model chi-squared $=125.53$ and $p=2.1$ E-25. CERAD composite score-based MCI classification was calculated using a predicted probability cut-off value $>0.5$. Finally, it was tested whether $G S T O 1^{*} C$ or $A P O E 4$ would still be found to associate with MCI, when study individuals were classified on the basis of either the MMSE logistic regression or CERAD composite score. Again, binary logistic regression analyses were used with $G S T O 1{ }^{*} C$ or $A P O E 4$ as predictor variable and the respective classification as outcome (Table 4). The calculations of associations between the SNPs and MCI are part of an exploratory analysis, which was not corrected for multiple testing $(\alpha=0.05)$. Further testing in a new sample cohort will be necessary to confirm our findings. Furthermore, a logistic regression analysis was 
performed on $G S T O 1{ }^{*} C$ or $A P O E 4$ with 69 controls and 71 LOAD patients. SPSS Statistics 22 (IBM) was used for these calculations.

\section{ACKNOWLEDGMENTS}

We thank Aner Gurvitz for critically reading and editing the manuscript.

\section{CONFLICTS OF INTEREST}

The funders had no role in study design, data collection and analysis, decision to publish, or preparation of the manuscript. All authors declare no conflict of interest and concur with this submission.

\section{GRANT SUPPORT}

This work was supported by the FP7 framework program of the European Commission (Grant FP7PEOPLE-2011-IAPP-286337).

\section{REFERENCES}

1. Qiu C, Kivipelto $M$ and von Strauss E. Epidemiology of Alzheimer's disease: occurrence, determinants, and strategies toward intervention. Dialogues in clinical neuroscience. 2009; 11:111-128.

2. Seltzer B and Sherwin I. A comparison of clinical features in early- and late-onset primary degenerative dementia. One entity or two? Archives of neurology. 1983; 40:143-146.

3. Bloom GS. Amyloid-beta and tau: the trigger and bullet in Alzheimer disease pathogenesis. JAMA neurology. 2014; 71:505-508.

4. Suh YH and Checler F. Amyloid precursor protein, presenilins, and alpha-synuclein: molecular pathogenesis and pharmacological applications in Alzheimer's disease. Pharmacological reviews. 2002; 54:469-525.

5. Chouraki V and Seshadri S. Genetics of Alzheimer's disease. Advances in genetics. 2014; 87:245-294.

6. Gatz M, Reynolds CA, Fratiglioni L, Johansson B, Mortimer JA, Berg S, Fiske A and Pedersen NL. Role of genes and environments for explaining Alzheimer disease. ArchGenPsychiatry. 2006; 63:168-174.

7. Lambert JC, Heath S, Even G, Campion D, Sleegers K, Hiltunen M, Combarros O, Zelenika D, Bullido MJ, Tavernier B, Letenneur L, Bettens K, Berr C, Pasquier F, Fievet N, Barberger-Gateau P, et al. Genome-wide association study identifies variants at CLU and CR1 associated with Alzheimer's disease. Nature genetics. 2009; 41:1094-1099.

8. Harold D, Abraham R, Hollingworth P, Sims R, Gerrish A, Hamshere ML, Pahwa JS, Moskvina V, Dowzell K, Williams A, Jones N, Thomas C, Stretton A, Morgan AR,
Lovestone S, Powell J, et al. Genome-wide association study identifies variants at CLU and PICALM associated with Alzheimer's disease. Nature genetics. 2009; 41:10881093.

9. Seshadri S, Fitzpatrick AL, Ikram MA, DeStefano AL, Gudnason V, Boada M, Bis JC, Smith AV, Carassquillo MM, Lambert JC, Harold D, Schrijvers EM, RamirezLorca R, Debette S, Longstreth WT, Jr., Janssens AC, et al. Genome-wide analysis of genetic loci associated with Alzheimer disease. Jama. 2010; 303:1832-1840.

10. Hollingworth P, Harold D, Sims R, Gerrish A, Lambert JC, Carrasquillo MM, Abraham R, Hamshere ML, Pahwa JS, Moskvina V, Dowzell K, Jones N, Stretton A, Thomas C, Richards A, Ivanov D, et al. Common variants at ABCA7, MS4A6A/MS4A4E, EPHA1, CD33 and CD2AP are associated with Alzheimer's disease. Nature genetics. 2011; 43:429-435.

11. Naj AC, Jun G, Beecham GW, Wang LS, Vardarajan BN, Buros J, Gallins PJ, Buxbaum JD, Jarvik GP, Crane PK, Larson EB, Bird TD, Boeve BF, Graff-Radford NR, De Jager PL, Evans D, et al. Common variants at MS4A4/ MS4A6E, CD2AP, CD33 and EPHA1 are associated with late-onset Alzheimer's disease. Nature genetics. 2011; 43:436-441.

12. Miyashita A, Koike A, Jun G, Wang LS, Takahashi S, Matsubara E, Kawarabayashi T, Shoji M, Tomita N, Arai H, Asada T, Harigaya Y, Ikeda M, Amari M, Hanyu H, Higuchi S, et al. SORL1 is genetically associated with late-onset Alzheimer's disease in Japanese, Koreans and Caucasians. PloS one. 2013; 8:e58618.

13. Lambert JC, Ibrahim-Verbaas CA, Harold D, Naj AC, Sims R, Bellenguez C, DeStafano AL, Bis JC, Beecham GW, Grenier-Boley B, Russo G, Thorton-Wells TA, Jones N, Smith AV, Chouraki V, Thomas C, et al. Meta-analysis of 74,046 individuals identifies 11 new susceptibility loci for Alzheimer's disease. Nature genetics. 2013; 45:1452-1458.

14. AlzGene. (2015). AlzGene - Field synopsis of genetic association studies in $\mathrm{AD}$, http://www.alzgene.org/, accession date: 20.03.2015

15. Reitz C. Genetic loci associated with Alzheimer's disease. Future neurology. 2014; 9:119-122.

16. Jack CR, Jr., Albert MS, Knopman DS, McKhann GM, Sperling RA, Carrillo MC, Thies B and Phelps $\mathrm{CH}$. Introduction to the recommendations from the National Institute on Aging-Alzheimer's Association workgroups on diagnostic guidelines for Alzheimer's disease. Alzheimer's \& dementia. 2011; 7:257-262.

17. Dubois B, Feldman HH, Jacova C, Hampel H, Molinuevo JL, Blennow K, DeKosky ST, Gauthier S, Selkoe D, Bateman R, Cappa S, Crutch S, Engelborghs S, Frisoni GB, Fox NC, Galasko D, et al. Advancing research diagnostic criteria for Alzheimer's disease: the IWG-2 criteria. The Lancet Neurology. 2014; 13:614-629.

18. Folstein MF, Folstein SE and McHugh PR. "Mini-mental state". A practical method for grading the cognitive state 
of patients for the clinician. Journal of psychiatric research. 1975; 12:189-198.

19. Aebi C. (2002). Validierung der neuropsychologischen Testbatterie CERAD-NP: eine Multi-Center Studie. (Switzerland: University of Basel, Faculty of Humanities).

20. Li YJ, Oliveira SA, Xu P, Martin ER, Stenger JE, Scherzer CR, Hauser MA, Scott WK, Small GW, Nance MA, Watts RL, Hubble JP, Koller WC, Pahwa R, Stern MB, Hiner $\mathrm{BC}$, et al. Glutathione S-transferase omega-1 modifies age-at-onset of Alzheimer disease and Parkinson disease. HumMolGenet. 2003; 12:3259-3267.

21. Capurso C, Panza F, Seripa D, Frisardi V, Imbimbo BP, Verdile G, Vendemiale G, Pilotto A and Solfrizzi V. Polymorphisms in glutathione S-transferase omega-1 gene and increased risk of sporadic Alzheimer disease. RejuvenationRes. 2010; 13:645-652.

22. Piacentini S, Polimanti R, Squitti R, Mariani S, Migliore S, Vernieri F, Rossini PM, Manfellotto D and Fuciarelli M. GSTO1*E155del polymorphism associated with increased risk for late-onset Alzheimer's disease: association hypothesis for an uncommon genetic variant. Neuroscience letters. 2012; 506:203-207.

23. Winblad B, Palmer K, Kivipelto M, Jelic V, Fratiglioni L, Wahlund LO, Nordberg A, Backman L, Albert M, Almkvist O, Arai H, Basun H, Blennow K, de LM, DeCarli C, Erkinjuntti T, et al. Mild cognitive impairmentbeyond controversies, towards a consensus: report of the International Working Group on Mild Cognitive Impairment. JInternMed. 2004; 256:240-246.

24. Petersen RC and Morris JC. Mild cognitive impairment as a clinical entity and treatment target. Archives of neurology. 2005; 62:1160-1163; discussion 1167.

25. Corder EH, Saunders AM, Risch NJ, Strittmatter WJ, Schmechel DE, Gaskell PC, Jr., Rimmler JB, Locke PA, Conneally PM, Schmader KE and et al. Protective effect of apolipoprotein E type 2 allele for late onset Alzheimer disease. Nature genetics. 1994; 7:180-184.

26. Eisenstein M. Genetics: finding risk factors. Nature. 2011; 475:S20-22.

27. Boyle PA, Buchman AS, Wilson RS, Kelly JF and Bennett DA. The APOE epsilon4 allele is associated with incident mild cognitive impairment among community-dwelling older persons. Neuroepidemiology. 2010; 34:43-49.

28. Veitinger M, Oehler R, Umlauf E, Baumgartner R, Schmidt G, Gerner C, Babeluk R, Attems J, Mitulovic G, Rappold E, Lamont $\mathrm{J}$ and Zellner M. A platelet protein biochip rapidly detects an Alzheimer's disease-specific phenotype. Acta Neuropathol. 2014; 128:665-677. doi: 610.1007/s0040100014-01341-00408. Epub 02014 Sep 00424.

29. Li YJ, Scott WK, Zhang L, Lin PI, Oliveira SA, Skelly T, Doraiswamy MP, Welsh-Bohmer KA, Martin ER, Haines JL, Pericak-Vance MA and Vance JM. Revealing the role of glutathione S-transferase omega in age-at-onset of Alzheimer and Parkinson diseases. NeurobiolAging. 2006;
27:1087-1093.

30. Kolsch H, Linnebank M, Lutjohann D, Jessen F, Wullner U, Harbrecht U, Thelen KM, Kreis M, Hentschel F, Schulz A, von Bergmann K, Maier W and Heun R. Polymorphisms in glutathione S-transferase omega-1 and $\mathrm{AD}$, vascular dementia, and stroke. Neurology. 2004; 63:2255-2260.

31. Ozturk A, Desai PP, Minster RL, Dekosky ST and Kamboh MI. Three SNPs in the GSTO1, GSTO2 and PRSS11 genes on chromosome 10 are not associated with age-at-onset of Alzheimer's disease. NeurobiolAging. 2005; 26:1161-1165.

32. Allen M, Zou F, Chai HS, Younkin CS, Miles R, Nair AA, Crook JE, Pankratz VS, Carrasquillo MM, Rowley CN, Nguyen T, Ma L, Malphrus KG, Bisceglio G, Ortolaza AI, Palusak R, et al. Glutathione S-transferase omega genes in Alzheimer and Parkinson disease risk, age-at-diagnosis and brain gene expression: an association study with mechanistic implications. MolNeurodegener. 2012; 7:13.

33. Seshadri S, Beiser A, Selhub J, Jacques PF, Rosenberg IH, D'Agostino RB, Wilson PW and Wolf PA. Plasma homocysteine as a risk factor for dementia and Alzheimer's disease. NEnglJMed. 2002; 346:476-483.

34. Sollberger M and Monsch A. (2007). Diagnostic Manual for Dementia. Memory Clinic - Neuropsychology Center, Basel, University Hospital Basel, Switzerland).

35. Jak AJ, Bondi MW, Delano-Wood L, Wierenga C, CoreyBloom J, Salmon DP and Delis DC. Quantification of five neuropsychological approaches to defining mild cognitive impairment. AmJGeriatrPsychiatry. 2009; 17:368-375.

36. Normen zur CERAD-Plus Testbatterie. In: Deskriptive statistische Kennwerte der Normpopulation N, Berechnungsformeln, https://www.memoryclinic.ch/ de/main-navigation/neuropsychologen/cerad-plus/ auswertungprogramme/cerad-plus-online/, access date: 26.02.2016.

37. Tombaugh TN and McIntyre NJ. The mini-mental state examination: a comprehensive review. Journal of the American Geriatrics Society. 1992; 40:922-935.

38. Nelson A, Fogel BS and Faust D. Bedside cognitive screening instruments. A critical assessment. The Journal of nervous and mental disease. 1986; 174:73-83.

39. Ehrensperger MM, Berres M, Taylor KI and Monsch AU. Early detection of Alzheimer's disease with a total score of the German CERAD. Journal of the International Neuropsychological Society. 2010; 16:910-920.

40. Corder EH, Saunders AM, Strittmatter WJ, Schmechel DE, Gaskell PC, Small GW, Roses AD, Haines JL and PericakVance MA. Gene dose of apolipoprotein E type 4 allele and the risk of Alzheimer's disease in late onset families. Science. 1993; 261:921-923.

41. Small BJ, Mobly JL, Laukka EJ, Jones S and Backman L. Cognitive deficits in preclinical Alzheimer's disease. Acta neurologica Scandinavica Supplementum. 2003; 179:29-33.

42. Attems J and Jellinger KA. The overlap between vascular disease and Alzheimer's disease-lessons from pathology. 
BMC medicine. 2014; 12:206.

43. Kolsch H, Larionov S, Dedeck O, Orantes M, Birkenmeier G, Griffin WS and Thal DR. Association of the glutathione S-transferase omega-1 Ala140Asp polymorphism with cerebrovascular atherosclerosis and plaque-associated interleukin-1 alpha expression. Stroke. 2007; 38:2847-2850.

44. Fillenbaum GG, Peterson B and Morris JC. Estimating the validity of the clinical Dementia Rating Scale: the CERAD experience. Consortium to Establish a Registry for Alzheimer's Disease. Aging (Milano). 1996; 8:379-385.

45. Rossetti HC, Munro Cullum C, Hynan LS and Lacritz LH. The CERAD Neuropsychologic Battery Total Score and the progression of Alzheimer disease. Alzheimer disease and associated disorders. 2010; 24:138-142.

46. DESTATIS Statistisches Bundesamt. Generationensterbetafeln für Deutschland, Modellrechnungen für die Geburtsjahrgänge 1896 - 2009. DESTATIS Statistisches Bundesamt), pp. 1-920.

47. Sando SB, Melquist S, Cannon A, Hutton ML, Sletvold O, Saltvedt I, White LR, Lydersen S and Aasly JO. APOE epsilon 4 lowers age at onset and is a high risk factor for Alzheimer's disease; a case control study from central Norway. BMC neurology. 2008; 8:9.

48. Hallman DM, Boerwinkle E, Saha N, Sandholzer C, Menzel HJ, Csazar A and Utermann G. The apolipoprotein E polymorphism: a comparison of allele frequencies and effects in nine populations. American journal of human genetics. 1991; 49:338-349.

49. Wolfsgruber S, Jessen F, Wiese B, Stein J, Bickel H, Mosch E, Weyerer S, Werle J, Pentzek M, Fuchs A, Kohler M, Bachmann C, Riedel-Heller SG, Scherer M, Maier W and
Wagner M. The CERAD Neuropsychological Assessment Battery Total Score Detects and Predicts Alzheimer Disease Dementia with High Diagnostic Accuracy. AmJGeriatrPsychiatry. 2014; 22:1017-28. doi: 10.1016/j. jagp.2012.08.021.

50. McKhann G, Drachman D, Folstein M, Katzman R, Price D and Stadlan EM. Clinical diagnosis of Alzheimer's disease: report of the NINCDS-ADRDA Work Group under the auspices of Department of Health and Human Services Task Force on Alzheimer's Disease. Neurology. 1984; 34:939944.

51. Memory Clinic University of Basel. CERAD-Plus Online. http://www.memoryclinic.ch/content/view/19/51/, access date: 09.04.2015.

52. Crook R, Hardy J and Duff K. Single-day apolipoprotein E genotyping. J NeurosciMethods. 1994; 53:125-127.

53. Little S. Amplification-refractory mutation system (ARMS) analysis of point mutations. Current protocols in human genetics / editorial board, Jonathan L Haines [et al]. 2001; Chapter 9:Unit 9.8.

54. Wickham H. The Split-Apply-Combine Strategy for Data Analysis. Journal of Statistical Software. 2011; 40:29.

55. Graffelman J. Exploring Diallelic Genetic Markers: The HardyWeinberg Package. Journal of Statistical Software. 2015; 64:1-23.

56. R Core Team. (2013). R: A language and environment for statistical computing. R Foundation for Statistical Computing. 